\title{
Replacing annual shut-in well tests by analysis of regular injection data: field-case feasibility study
}

\author{
Dmitry Silin ${ }^{1}$, Chin-Fu Tsang ${ }^{1}$, and Harlan Gerrish ${ }^{2}$
}

\section{Introduction}

Regulations governing deep injection of industrial wastes for disposal require regular tests for monitoring the formation hydraulic properties changes in the vicinity of the wellbore. Such a monitoring is performed through transient pressure well testing, a procedure that is routinely used in the environmental and oil industries. In such tests, the pumping pressures and rates are recorded and analyzed to estimate the transmissivity and storativity of the rock in the vicinity of the wellbore. Numerous methods for analyzing such data have been developed since the pioneering paper by Theis (1935). The well test analysis methods are summarized in several monographs, see, e.g., Earlougher (1977) and Matthews (1967).

Traditional well test analysis methods are often based on estimating the slope of the pressure fall-off curve in a special time scale, e.g., using the Horner plot method (Horner, 1951). Such an approach is justified by asymptotic analysis of the pressure change relative to a uniform initial pressure distribution. However, in reality, such an initial condition may not hold true because the operations preceding the test make the pressure distribution not uniform. It has been demonstrated in Silin and Tsang (2002, 2003) that in the Horner plot method, this circumstance partially explains the deviation of the data points from the theoretically predicted straight line. A new method has been proposed to analyze well test data accounting for the pre-test operations. This method has been validated using synthetic and field well test data.

In this paper, we demonstrate how the method can be applied to analyze regular pumping data from an injection field to estimate the formation's hydraulic properties without interrupting the operations. In this estimation, we use the code ODA developed at Berkeley Lab. This code implements the methods and algorithms developed by Silin and Tsang $(2002,2003)$.

The paper is organized as follows. In the next section, we present a brief overview of the method and describe the procedure used in the analysis. Then, in the following section, we present the analysis of data from several injection wells. The results of this analysis are summarized in our conclusions.

\section{Description of the Method}

The procedure we use in this study was designed to estimate formation hydraulic properties from regular operations data. The recovered parameters include formation transmissivity and storativity, skin factor, and an average reservoir pressure. Additionally, the method estimates an effective pre-test pumping rate, which can be used for a posteriori verification of the quality of fitting. We only briefly describe the method; for details, see Silin and Tsang $(2002,2003)$.

\footnotetext{
${ }^{1}$ Lawrence Berkeley National Laboratory, 1 Cyclotron Road, MS 90-1116, Berkeley, CA 94720

${ }^{2}$ U.S. Environmental Protection Agency, 77 West Jackson Street, Chicago, IL 60604
} 
The procedure consists of several steps. First, a data set has to be selected. Each data point has three components: time of measurement, injection pressure, and injection rate. The data set must include transient changes in the pressures and flow rates. If the flow rates are not very high and the injected fluid is practically incompressible, the bottomhole pressure can be calculated from the instantaneous wellhead pressure. In fact, if an average reservoir pressure estimate is not required, the wellhead injection pressures can be used without any adjustments.

A distinctive feature of the method is that an effective injection rate, denoted by $Q_{-1}$, is introduced to account for the pre-test pumping. This parameter plays an intermediate role in the fitting procedure. If some information about the flow rates before the test interval is available, the magnitude of the discrepancy between these actual rates and $Q_{-1}$ can be used as an additional measure of the quality of analysis. A small discrepancy confirms a good quality of fitting, whereas a large discrepancy indicates that either some minimization parameters need to be changed or a different data interval has to be selected for the test.

The selected data interval is split into two parts: the beginning phase and the test phase. The test-phase data points of the pressure curve are used in a best-fitting procedure to estimate formation parameters, whereas the beginning-phase data interval is used for intermediate calculations only. Let us denote by $t_{0}$ and $t_{2}$, respectively, the beginning and the end times of the whole selected interval, and denote by $t_{1}$ the splitting time. Then the modified radial flow solution has the following form (Silin and Tsang, 2002; 2003):

$$
p(t)=p\left(t_{0}\right)+A Q_{-1} \operatorname{Ei}\left(-\frac{B}{t-t_{0}}\right)+A \int_{t_{0}}^{t} \frac{\exp \left(-\frac{B}{t-\tau}\right)}{t-\tau} Q(\tau) d \tau+s A Q(t), \quad t_{1} \leq t \leq t_{2}
$$

Here $p$ and $Q$ are the injection pressures and rates, respectively. We adopt the convention that the pumping rate is positive if the fluid is injected. The skin factor $s$, pre-test pumping rate $Q_{-1}$, and coefficients $A$ and $B$ are the fitting parameters. Skin factor is an optional parameter and can be excluded from the fitting procedure by setting it at zero. If the pressures and rates were measured between $t_{1}$ and $t_{2}$ at points $\theta_{1}, \theta_{2}, \ldots, \theta_{N}$, then the quality of fitting can be estimated using criterion

$$
J=\frac{1}{N} \sum_{i=1}^{N}\left[p\left(\theta_{i}\right)-p_{\text {data }}\left(\theta_{i}\right)\right]^{2}
$$

where $p_{\text {data }}$ is the measured injection pressure. An effective minimization algorithm for the functional (2) was proposed in Silin and Tsang (2002, 2003). This algorithm has been implemented in the code ODA, which was used as the main tool in this study. The coefficients of transmissivity $T$ and storativity $S$ are related to $A$ and $B$ as follows:

$$
T=\frac{1}{4 \pi A}, \quad S=\frac{2 B}{\pi r^{2} A}
$$


In the last equation, $r$ is the effective wellbore radius.

\section{Analysis of Field Data}

The method described in the previous section is tested by the following procedure. First, the regular injection operations data are analyzed using the ODA code to estimate the formation parameters. Then, these results are compared with results obtained independently from conventional analyses of fall-off tests. The discrepancies are studied to understand the sources of the differences and to determine which method is more accurate.

This procedure has been performed for the data from four deep waste disposal wells in Ohio, which have been in operation for over 10 years. The injected fluid is water with a dilute solution of chemicals. The injectant is treated by removal of particles before injection, so that the density and viscosity of the fluid practically equal those of water. The injection zone includes part of the Middle Run Formation and all of the Mt. Simon and Eau Claire Formations at depths 3,223 to 2,430 feet below the surface. Each of these formations extends laterally far beyond the vicinity of the injection site. The injection zone is subdivided into an effective injection interval and an arrestment interval. Fluid is injected directly into the active injection interval from the open-hole portions of the wells. The active injection interval is composed of the entire Mt. Simon Formation and portions of the underlying Middle Run Formation and the overlying Eau Claire Formation. The Mt. Simon Formation is composed of sandstone, and is between 2,813 and 3,153 feet deep, with porosities as high as $20 \%$ and averaging $12 \%$ for the entire formation. Permeabilities at Mt. Simon range from 0.0005 to $695 \mathrm{md}$ for core samples and average as much as $64 \mathrm{md}$ for the lowermost $183 \mathrm{ft}$ thick division. The underlying Middle Run Formation is composed of argillaceous sandstone and siltstone, with porosity of $2 \%$ and permeability about $10 \mathrm{md}$ in the uppermost $70 \mathrm{ft}$ layer. The Eau Claire portion of the active injection interval is between 2,775 and 2,813 feet in depth. This layer is composed mainly of sandstones with porosities ranging from 3.5 to $17 \%$ and an average permeability of $300 \mathrm{md}$. The passive injection interval is between 2,640 and 2,775 feet deep and consists of two layers of the Eau Claire Formation, which are composed of sandstone and silty sandstones with generally moderate porosity $(>8 \%)$ and low average permeability (1-5 md, horizontal, and $0.003-0.004 \mathrm{md}$, vertical) caused by occlusion of pore spaces by shale and dolomite.

The portion of the injection zone serving as the arrestment interval consists of three layers of the Eau Claire Formation between the depths of 2,430 and 2,630 feet. These layers consist mostly of dolomite with some interbedded shale and sand, and contain confining units (dense carbonates and shales). Analyses of core samples indicate that the effective vertical permeability of the dolomite is less than $0.00005 \mathrm{md}$. Above the injection zone is a confining zone made up of two layers in the lower part of the Knox Dolomite from 2,100 to 2,430 feet in depth. These layers are continuous for hundreds of square miles. Information about the depths and thicknesses of the injection intervals is summarized in

Table 1. The average injection interval depth was used to calculate the downhole pressure. In most well test analysis methods, including the one described in the previous section, only the variation of the injection pressure is needed for estimates of all parameters except the ambient reservoir pressure. 
Table 1. The Depths of Injection Zones for Wells A-D

\begin{tabular}{|c|c|c|l|l|}
\hline & $\begin{array}{l}\text { Minimal } \\
\text { injection } \\
\text { interval depth } \\
{[\mathrm{ft}]}\end{array}$ & $\begin{array}{l}\text { Maximal } \\
\text { injection } \\
\text { interval depth } \\
{[\mathrm{ft}]}\end{array}$ & $\begin{array}{l}\text { Injection } \\
\text { interval } \\
\text { thickness [ft] }\end{array}$ & $\begin{array}{l}\text { Average } \\
\text { injection } \\
\text { interval depth } \\
{[\mathrm{ft}]}\end{array}$ \\
\hline Well A & 2783 & 3077 & 294 & 2930 \\
\hline Well B & 2813 & 3125 & 312 & 2969 \\
\hline Well C & 2810 & 3140 & 330 & 2975 \\
\hline Well D & 2885 & 3159 & 274 & 3022 \\
\hline
\end{tabular}

For ODA data analysis, we used hourly records of injection pressures and rates collected over time intervals of three to four days. No information about the operations immediately before or after data intervals is available. Since in some cases the consecutive data points vary significantly, a running averaging over a three-hour window was applied. Usually, the fitting of such smoothed data is slightly more stable with respect to the selection of the intervals $\left(t_{0}, t_{1}\right)$ and $\left(t_{1}, t_{2}\right)$. The principal output parameters of the fitting procedure are the transmissivity and storativity of the near-wellbore formation, the skin factor, and the ambient reservoir pressure. In all runs, where information about the pre-test injection rate was available, the quality of fitting was confirmed by good agreement between this actual rate and the estimated effective pre-test injection rate $Q_{-1}$.

For well A, two data intervals of 72 and 96 hours, with approximately 13 months between the two intervals, were analyzed. We denote the data intervals by "Jun01" and "Aug02," respectively. Results from analysis are presented in Table 2. "No" in the skin factor column means that skin factor was not used in data matching. The estimated skin factor is small in all runs.

The results of Runs 1 through 6 are presented in Figure 1. Note that in Figure 1(b), the part of the curve between $t_{2}=70 \mathrm{hrs}$ and the end of the data interval is $a$ prediction based on fitting the data only between $t_{1}=49 \mathrm{hrs}$ and $t_{2}$ (Run 3 , Table 2). The matching curves corresponding to all these six runs practically collapse and coincide with the data curve (Figure 1 (c)). The results obtained from June 2001 data on different test intervals (runs 1-6, Table 2) are in a good agreement, but they are different from the results obtained from August 2002 data (Runs 7-8). Table 2 results can be compared with the results of the fall-off tests from previous years analyzed independently using conventional methods (Table 3). Note that the variation of the results of conventional analysis performed in different years also is significant: the transmissivity estimate of October 1996 is almost twice higher than that of December 1992. 
Table 2. Results of Regular Data Analysis Using Code ODA for Well A

\begin{tabular}{|c|c|c|c|c|c|c|c|}
\hline $\begin{array}{c}\text { Run \# } \\
\Downarrow\end{array}$ & $\begin{array}{c}\text { Data } \\
\text { interval }\end{array}$ & $\begin{array}{c}\boldsymbol{t}_{\mathbf{0}} \\
{[\mathbf{h r s}]}\end{array}$ & $\begin{array}{c}\boldsymbol{t}_{\mathbf{1}} \\
{[\mathbf{h r s}]}\end{array}$ & $\begin{array}{c}\boldsymbol{t}_{\mathbf{2}} \\
{[\mathbf{h r s}]}\end{array}$ & $\begin{array}{c}\text { Transmissivity } \\
{[\mathbf{d}-\mathbf{f t} / \mathbf{c p}]}\end{array}$ & $\begin{array}{c}\text { Skin } \\
\text { factor }\end{array}$ & $\begin{array}{c}\text { Ambient } \\
\text { pressure } \\
{[\mathbf{p s i}]}\end{array}$ \\
\hline 1 & Jun01 & 0 & 23 & 95 & 7.97 & No & 1403 \\
\hline 2 & Jun01 & 0 & 23 & 95 & 7.49 & -0.055 & 1396 \\
\hline 3 & Jun01 & 43 & 49 & 70 & 8.02 & No & 1418 \\
\hline 4 & Jun01 & 43 & 49 & 70 & 6.98 & 0.31 & 1385 \\
\hline 5 & Jun01 & 15 & 23 & 65 & 7.34 & No & 1403 \\
\hline 6 & Jun01 & 15 & 23 & 65 & 7.05 & 0.098 & 1393 \\
\hline 7 & Aug02 & 43 & 46 & 66 & 18.49 & No & 1509 \\
\hline 8 & Aug02 & 20 & 33 & 55 & 16.05 & No & 1441 \\
\hline
\end{tabular}

Table 3. Results of Fall-Off Well Test Analysis for Well A

\begin{tabular}{|l|l|l|l|l|l|l|l|l|l|}
\hline $\begin{array}{l}\text { Date of } \\
\text { the test } \Rightarrow\end{array}$ & $\begin{array}{l}\text { Apr } \\
\mathbf{1 9 9 1}\end{array}$ & $\begin{array}{l}\text { May } \\
\mathbf{1 9 9 2}\end{array}$ & $\begin{array}{l}\text { Dec } \\
\mathbf{1 9 9 2}\end{array}$ & $\begin{array}{l}\text { Jan } \\
\mathbf{1 9 9 4}\end{array}$ & $\begin{array}{l}\text { Nov } \\
\mathbf{1 9 9 4}\end{array}$ & $\begin{array}{l}\text { Nov } \\
\mathbf{1 9 9 5}\end{array}$ & $\begin{array}{l}\text { Oct } \\
\mathbf{1 9 9 6}\end{array}$ & $\begin{array}{l}\text { Oct } \\
\mathbf{1 9 9 7}\end{array}$ & $\begin{array}{l}\text { Oct } \\
\mathbf{1 9 9 8}\end{array}$ \\
\hline $\begin{array}{l}\text { Transmissivity } \\
\text { [d-ft/cp] }\end{array}$ & 12.26 & 9.13 & 7.89 & 12.06 & 12.05 & 15.57 & 17.59 & 13.88 & 12.28 \\
\hline $\begin{array}{l}\text { Skin } \\
\text { factor }\end{array}$ & -1.7 & -1.8 & -2.4 & -2.7 & -2.8 & -3.4 & -3.5 & -2.3 & -1.9 \\
\hline $\begin{array}{l}\text { Extrapolated } \\
\text { pressure [psi] }\end{array}$ & 1324 & 1350 & 1336 & 1394 & 1406 & 1423 & 1422 & 1445 & 1451 \\
\hline
\end{tabular}

Table 4. Results of Regular Data Analysis Using Code ODA for Well B: Result for Smoothed Data Are Labeled by ${ }^{\text {\& }}$

\begin{tabular}{|c|c|c|c|c|c|c|c|}
\hline $\begin{array}{c}\text { Run \# } \\
\Downarrow\end{array}$ & $\begin{array}{c}\text { Data } \\
\text { interval }\end{array}$ & $\begin{array}{c}\boldsymbol{t}_{\mathbf{0}} \\
{[\mathbf{h r s}]}\end{array}$ & $\begin{array}{c}\boldsymbol{t}_{\mathbf{1}} \\
{[\mathbf{h r s}]}\end{array}$ & $\begin{array}{c}\boldsymbol{t}_{\mathbf{2}} \\
{[\mathbf{h r s}]}\end{array}$ & $\begin{array}{c}\text { Transmissivity } \\
{[\mathbf{d}-\mathbf{f t} / \mathbf{c p}]}\end{array}$ & $\begin{array}{c}\text { Skin } \\
\text { factor }\end{array}$ & $\begin{array}{c}\text { Ambient } \\
\text { pressure } \\
{[\mathbf{p s i}]}\end{array}$ \\
\hline 1 & Jun01 & 0 & 23 & 95 & 14.56 & No & 1439 \\
\hline 2 & Jun01 & 0 & 23 & 95 & 18.75 & -1.29 & 1465 \\
\hline 3 & Jun01 & 30 & 44 & 70 & 14.24 & 0.16 & 1426 \\
\hline $4^{\&}$ & Jun01 & 30 & 44 & 70 & 10.92 & No & 1406 \\
\hline $5^{\&}$ & Jun01 & 30 & 44 & 70 & 10.92 & $1 . \mathrm{e}-10$ & 1406 \\
\hline 6 & Aug02 & 0 & 17 & 71 & 25.35 & -0.4 & 1523 \\
\hline $7^{\&}$ & Aug02 & 0 & 17 & 71 & 24.02 & -0.95 & 1522 \\
\hline $8^{\&}$ & Aug02 & 33 & 36 & 56 & 25.42 & -1.64 & 1534 \\
\hline
\end{tabular}

Table 5. Results of Fall-Off Well Test Analysis for Well B

\begin{tabular}{|l|l|l|l|l|l|l|l|l|l|l|}
\hline $\begin{array}{l}\text { Date of } \\
\text { the test } \Rightarrow\end{array}$ & $\begin{array}{l}\text { Aug } \\
\mathbf{1 9 9 1}\end{array}$ & $\begin{array}{l}\text { Dec } \\
\mathbf{1 9 9 1}\end{array}$ & $\begin{array}{l}\text { Mar } \\
\mathbf{1 9 9 3}\end{array}$ & $\begin{array}{l}\text { Mar } \\
\mathbf{1 9 9 4}\end{array}$ & $\begin{array}{l}\text { May } \\
\mathbf{1 9 9 5}\end{array}$ & $\begin{array}{l}\text { Jul } \\
\mathbf{1 9 9 6}\end{array}$ & $\begin{array}{l}\text { Apr } \\
\mathbf{1 9 9 7}\end{array}$ & $\begin{array}{l}\text { Apr } \\
\mathbf{1 9 9 8}\end{array}$ & $\begin{array}{l}\text { Apr } \\
\mathbf{1 9 9 9}\end{array}$ & $\begin{array}{l}\text { Apr } \\
\mathbf{2 0 0 0}\end{array}$ \\
\hline $\begin{array}{l}\text { Transmissivity } \\
\text { [d-ft/cp] }\end{array}$ & 6.04 & 6.73 & 10.00 & 9.43 & 16.71 & 9.74 & 17.44 & 12.50 & 13.53 & 13.41 \\
\hline $\begin{array}{l}\text { Skin } \\
\text { factor }\end{array}$ & -4.2 & -4.2 & -2.0 & -1.9 & -1.9 & 0.89 & -1.9 & -2.6 & -2.6 & -4.23 \\
\hline $\begin{array}{l}\text { Extrapolated } \\
\text { pressure [psi] }\end{array}$ & 1462 & 1462 & 1376 & 1391 & 1412 & 1401 & 1348 & 1376 & 1368 & 1381 \\
\hline
\end{tabular}




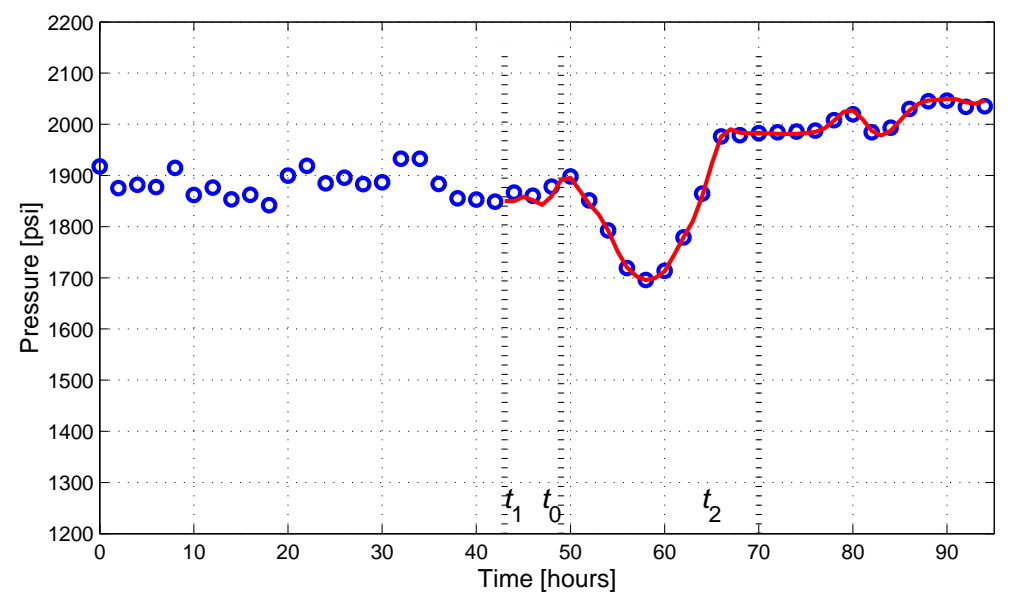

(a)

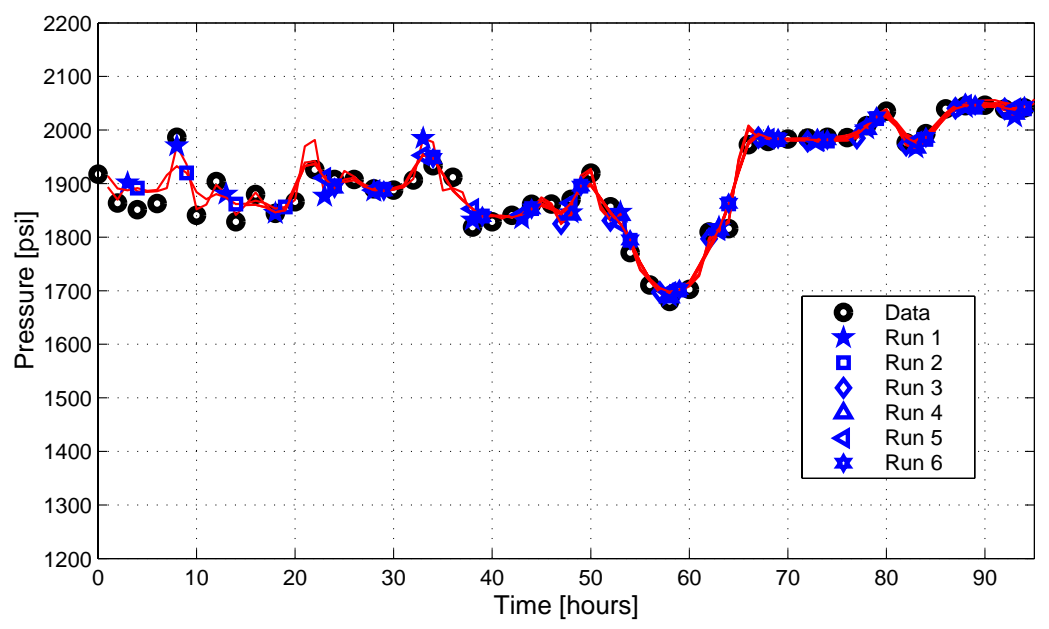

(b)

Figure 1. Examples of matching the Jun01 data from well A: (a) pressure fitting and prediction (Run 3, Table 2); and (b) pressure fitting for Runs 1-6 from Table 2.

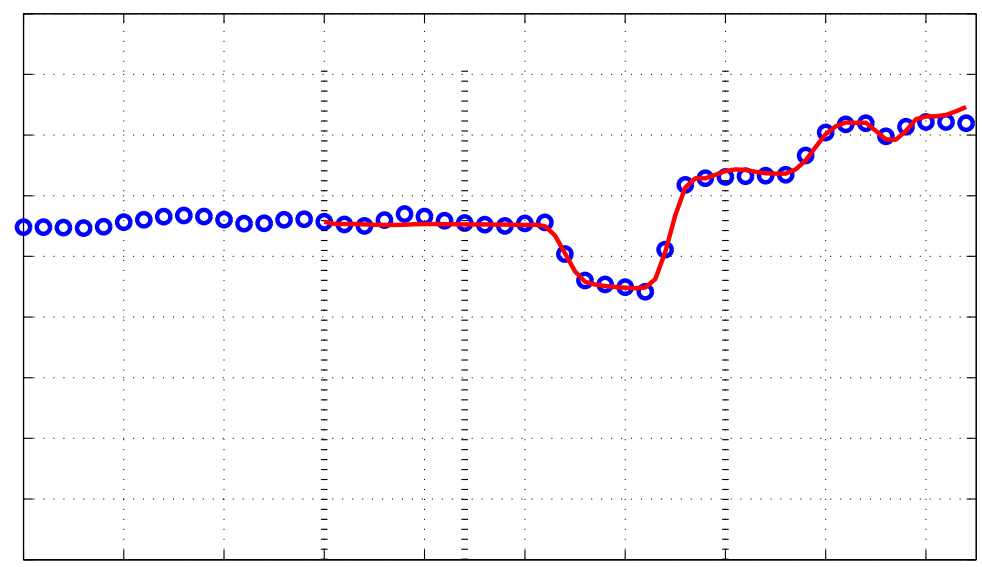

Figure 2. Matching the Jun01 data from well B (Run 4, Table 4). Note two different injection pressure regimes: between 0 and 50 hours and between 62 and 95 hours. 
Results of analyses performed for the Well B data are gathered in Table 4 and Table 5. Analysis of smoothed data does not significantly affect the results: compare Runs 4-5 with Run 3, and Runs 7-8 with Run 6. There are, however, noticeable variations in the results obtained on different intervals in July 2001. This difference can be caused by the changed injection regime: the pressures on the interval analyzed in the Runs 3 and 4 are lower than average injection pressure (Figure 2). As for Well A, the results of conventional analysis also vary significantly between different years: the transmissivity estimate obtained in April 1997 is almost three times higher than the estimates obtained in 1991 (Table 5).

The data from Well C were collected over two time intervals: 96 hours in July 2001 and 168 hours in August 2002. The 2002 data interval includes a fall-off test followed by resumption of regular operations. The ODA results are presented in Table 6 . Like for Well B, the difference between estimated parameters obtained from averaged (Runs 3 and 4) and "raw" data is not large, but the transmissivity estimates obtained at different data intervals are noticeably different. In the 2001 data, the injection pressures at later times are higher than those in the beginning of the interval, this can explain the difference between the transmissivity estimates in Run 2, and Runs 1 and 3-4.

In the 2002 data, the injection pressures on the intervals preceding the test data in Runs 5 and 6 (Figure 3(a)) are higher than the pressures during the shut-in before the testing interval in Runs 7 and 8 (Figure 3(b)). The transmissivity corresponding to the later times is smaller than the one obtained from the analysis of the fall-off curve. Results of conventional fall-off test analyses from previous years are presented in Table 7. Note that the transmissivity estimates obtained by analyzing the fall-off curve using ODA (Runs 5 and 6, Table 6) and the estimates of the same data by conventional methods (Aug 2002 column, Table 7) are close to each other, but the respective skin factor estimates are different. We believe that the reason for this discrepancy is that in conventional analysis the persistent residual influence of pumping before the test, which is rigorously accounted by ODA, is attributed exclusively to skin effect. The same circumstance could be the reason why the ambient pressures estimates obtained by ODA are, on average, higher than the extrapolated pressures in Table 7. The credibility of ODA results is confirmed by the fact that in both Runs 5 and 6 the obtained value of $Q_{-1}$ was $174 \mathrm{gpm}$ that is in a good agreement with the actual pre-test flow rates, Figure 3(c).

Operations data from Well D were collected over a 72-hour time interval in August 2002. Analysis results are presented in Table 8. Rate fluctuations are significant, between 86 and $140 \mathrm{gpm}$ (Figure 4); the corresponding fluctuations of the injection pressures are within 160 psi (Figure 5(a)). Note that the transmissivity estimates are practically the same both when skin factor is among the fitting parameters and when it is not. The optimal value of criterion (2) also remains with almost no change. At the same time, the difference between the estimated values of the skin factor in Runs 2 and 8 is quite significant. Again, data averaging appears neither to affect the estimates of transmissivity (see Runs 5 and 6), nor to affect data fitting in general (Figure 5). Due to large fluctuations, the fitting of smoothed data (Figure 5(b)) is visually better than the fitting of non-smoothed data (Figure 5(a)). 
Table 6. Results of Regular Data Analysis Using Code ODA for Well C Including Analysis of a FallOff Test Labeled by *

\begin{tabular}{|c|c|c|c|c|c|c|c|}
\hline $\begin{array}{c}\text { Run \# } \\
\Downarrow\end{array}$ & $\begin{array}{c}\text { Data } \\
\text { interval }\end{array}$ & $\begin{array}{c}\boldsymbol{t}_{\mathbf{0}} \\
{[\mathbf{h r s}]}\end{array}$ & $\begin{array}{c}\boldsymbol{t}_{\mathbf{1}} \\
{[\mathbf{h r s}]}\end{array}$ & $\begin{array}{c}\boldsymbol{t}_{\mathbf{2}} \\
{[\mathbf{h r s}]}\end{array}$ & $\begin{array}{c}\text { Transmissivity } \\
{[\mathbf{d}-\mathbf{f t} / \mathbf{c p}]}\end{array}$ & $\begin{array}{c}\text { Skin } \\
\text { factor }\end{array}$ & $\begin{array}{c}\text { Ambient } \\
\text { pressure } \\
{[\mathbf{p s i}]}\end{array}$ \\
\hline 1 & Jun01 & 25 & 35 & 62 & 14.70 & $1 . \mathrm{e}-10$ & 1602 \\
\hline 2 & Jun01 & 57 & 60 & 80 & 18.90 & $1 . \mathrm{e}-10$ & 1743 \\
\hline $3^{\&}$ & Jun01 & 25 & 35 & 62 & 14.72 & No & 1603 \\
\hline $4^{\&}$ & Jun01 & 57 & 60 & 80 & 12.41 & 0.22 & 1726 \\
\hline $5^{*}$ & Aug02 & 10 & 29 & 100 & 13.22 & No & 1403 \\
\hline $6^{*}$ & Aug02 & 10 & 29 & 100 & 13.84 & -0.019 & 1408 \\
\hline 7 & Aug02 & 100 & 120 & 167 & 7.26 & No & 1461 \\
\hline 8 & Aug02 & 100 & 120 & 167 & 6.49 & -0.13 & 1472 \\
\hline
\end{tabular}

Table 7. Results of Fall-Off Well Test Analysis for Well C

\begin{tabular}{|l|l|l|l|l|l|l|l|l|l|}
\hline $\begin{array}{l}\text { Date of } \\
\text { the test } \Rightarrow\end{array}$ & $\begin{array}{l}\text { Sep } \\
\mathbf{1 9 9 2}\end{array}$ & $\begin{array}{l}\text { Aug } \\
\mathbf{1 9 9 3}\end{array}$ & $\begin{array}{l}\text { Aug } \\
\mathbf{1 9 9 4}\end{array}$ & $\begin{array}{l}\text { Aug } \\
\mathbf{1 9 9 5}\end{array}$ & $\begin{array}{l}\text { May } \\
\mathbf{1 9 9 6}\end{array}$ & $\begin{array}{l}\text { Jul } \\
\mathbf{1 9 9 7}\end{array}$ & $\begin{array}{l}\text { Aug } \\
\mathbf{1 9 9 8}\end{array}$ & $\begin{array}{l}\text { Jul } \\
\mathbf{1 9 9 9}\end{array}$ & $\begin{array}{l}\text { Aug } \\
\mathbf{2 0 0 2}\end{array}$ \\
\hline $\begin{array}{l}\text { Transmissivity } \\
\text { [d-ft/cp] }\end{array}$ & 6.20 & 9.32 & 15.57 & 8.77 & 17.28 & 9.52 & 11.88 & 11.3 & 14.32 \\
\hline $\begin{array}{l}\text { Skin } \\
\text { factor }\end{array}$ & -2.8 & -1.3 & -2.3 & -4.4 & -2.5 & 1.3 & -3.7 & -3.3 & -3.9 \\
\hline $\begin{array}{l}\text { Extrapolated } \\
\text { pressure [psi] }\end{array}$ & 1441 & 1414 & 1359 & 1352 & 1370 & 1406 & 1300 & 1372 & 1377 \\
\hline
\end{tabular}

Table 8. Results of Regular Data Analysis Using Code ODA for Well D

\begin{tabular}{|c|c|c|c|c|c|c|c|}
\hline $\begin{array}{c}\text { Run \# } \\
\Downarrow\end{array}$ & $\begin{array}{c}\text { Data } \\
\text { interval }\end{array}$ & $\begin{array}{c}\boldsymbol{t}_{\mathbf{0}} \\
{[\mathbf{h r s}]}\end{array}$ & $\begin{array}{c}\boldsymbol{t}_{\mathbf{1}} \\
{[\mathbf{h r s}]}\end{array}$ & $\begin{array}{c}\boldsymbol{t}_{\mathbf{2}} \\
{[\mathbf{h r s}]}\end{array}$ & $\begin{array}{c}\text { Transmissivity } \\
{[\mathbf{d}-\mathbf{f t} / \mathbf{c p}]}\end{array}$ & $\begin{array}{c}\text { Skin } \\
\text { factor }\end{array}$ & $\begin{array}{c}\text { Ambient } \\
\text { pressure } \\
\text { [psi] }\end{array}$ \\
\hline 1 & Aug02 & 2 & 8 & 37 & 21.95 & No & 1593 \\
\hline 2 & Aug02 & 2 & 8 & 37 & 20.60 & 3.03 & 1532 \\
\hline 3 & Aug02 & 22 & 27 & 55 & 17.78 & No & 1492 \\
\hline 4 & Aug02 & 22 & 27 & 55 & 17.68 & 0.46 & 1483 \\
\hline $5^{\&}$ & Aug02 & 22 & 27 & 55 & 17.66 & No & 1489 \\
\hline $6^{\&}$ & Aug02 & 22 & 27 & 55 & 17.05 & 3.68 & 1413 \\
\hline
\end{tabular}

Table 9. Results of Fall-Off Well Test Analysis for Well D

\begin{tabular}{|l|c|c|c|c|}
\hline $\begin{array}{l}\text { Date of } \\
\text { the test } \Rightarrow\end{array}$ & Jun 1995 & Jun 1996 & Jun 1997 & Jun 1998 \\
\hline $\begin{array}{l}\text { Transmissivity } \\
\text { [d-ft/cp] }\end{array}$ & 13.92 & 12.35 & 15.43 & 7.29 \\
\hline $\begin{array}{l}\text { Skin } \\
\text { factor }\end{array}$ & -4.2 & -3.6 & -4.1 & -3.7 \\
\hline $\begin{array}{l}\text { Extrapolated } \\
\text { pressure [psi] }\end{array}$ & 1299 & 1220 & 1260 & 1180 \\
\hline
\end{tabular}




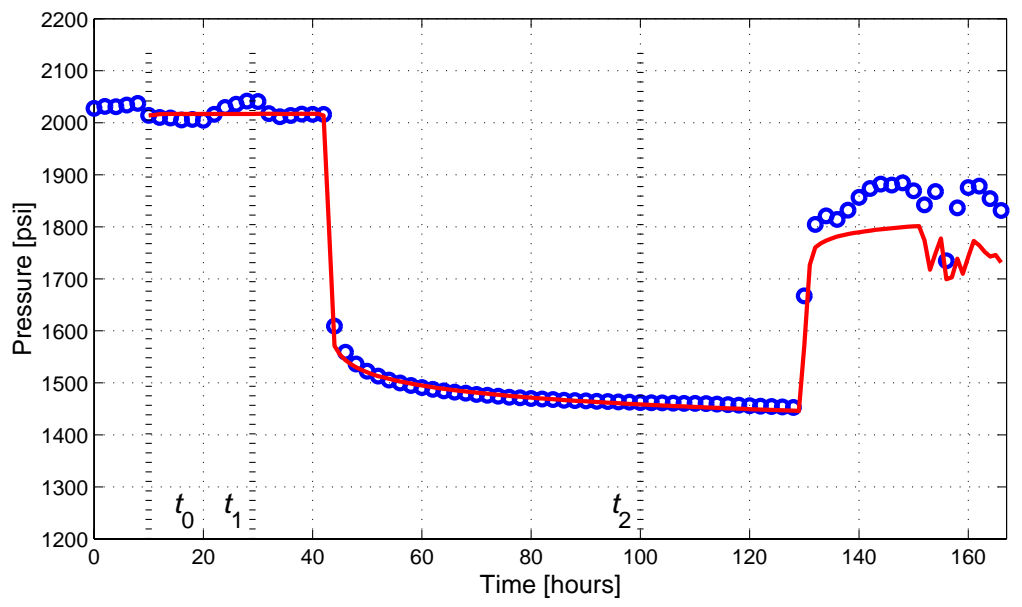

(a)

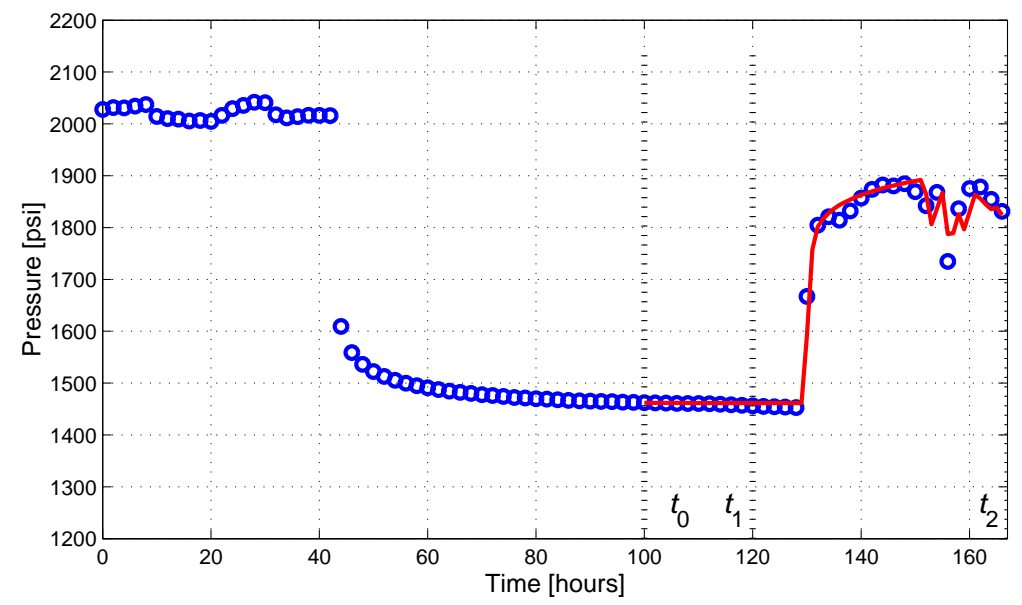

(b)

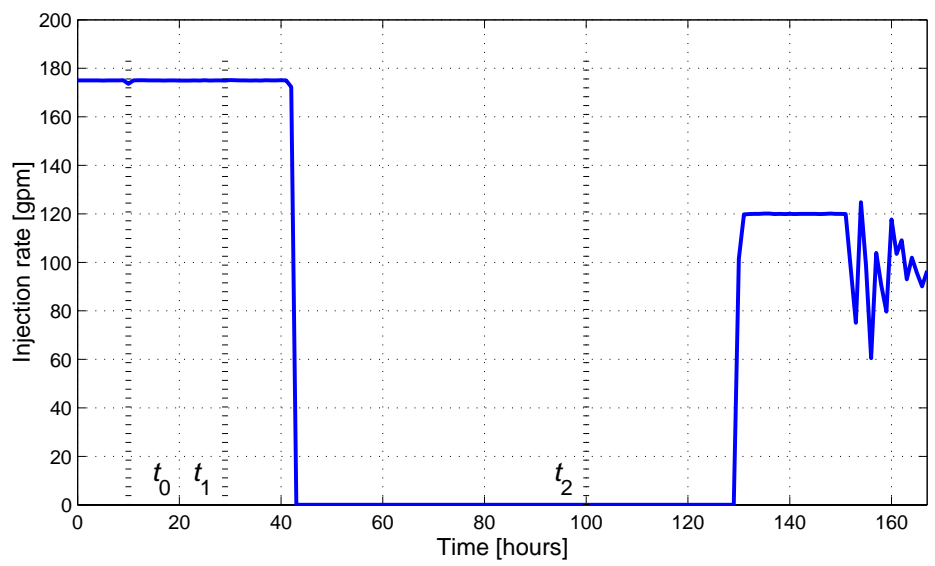

(c)

Figure 3. 2002 injection rate data for Well C: (a) matching the pressure fall-off curve; (b) matching pressure curve at the resumption of regular operations; (c) flow rate plot: the rates before $t_{0}$ fluctuate between 173 and $175 \mathrm{gpm}$. 


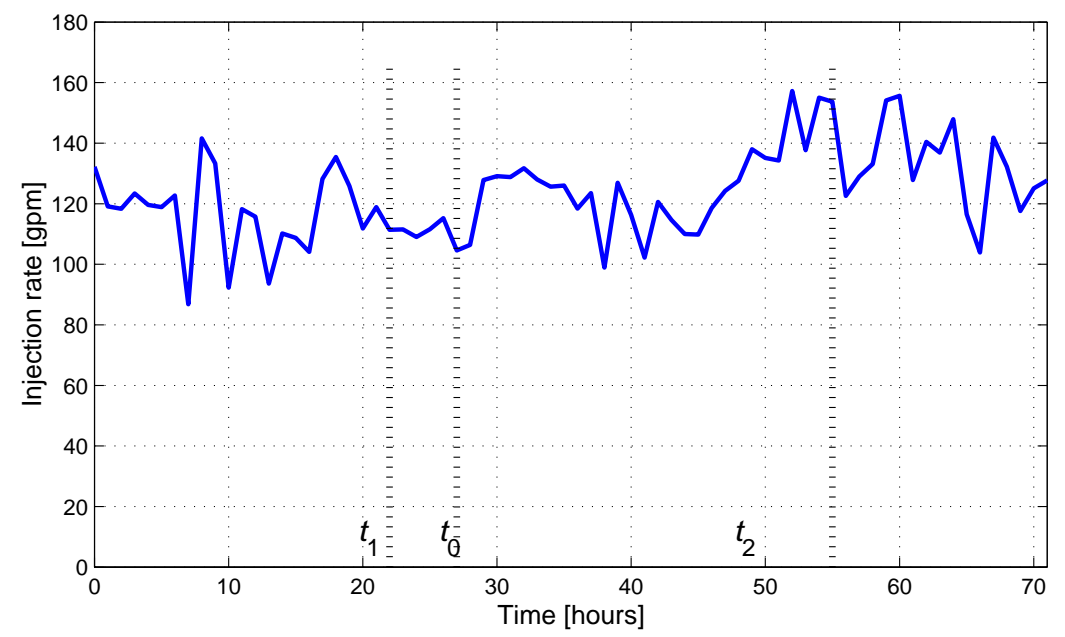

Figure 4. Well D: Significant rate fluctuations throughout entire data interval

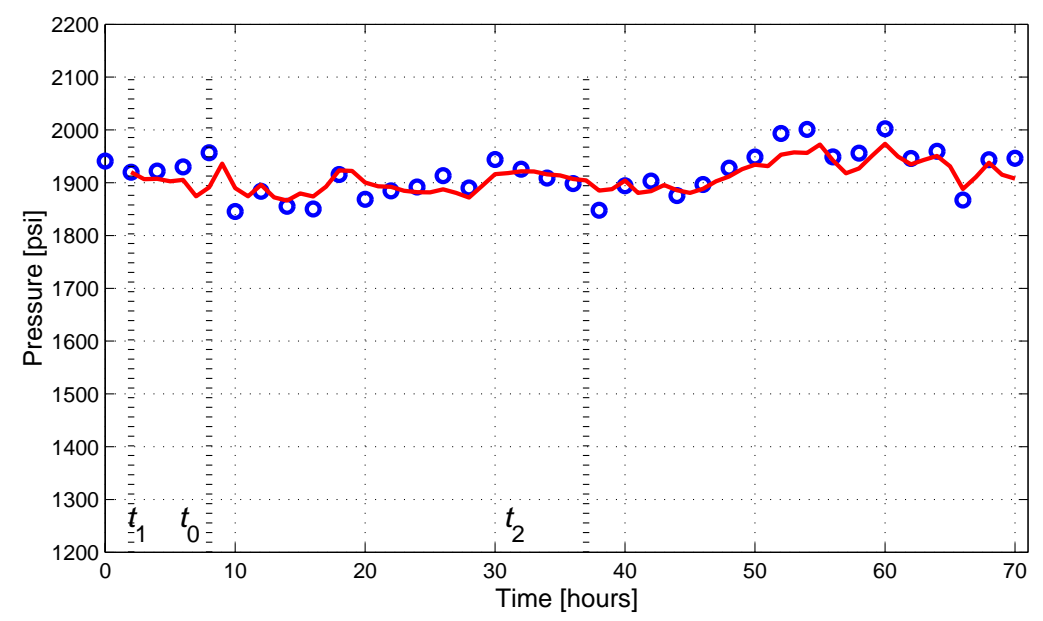

(a)

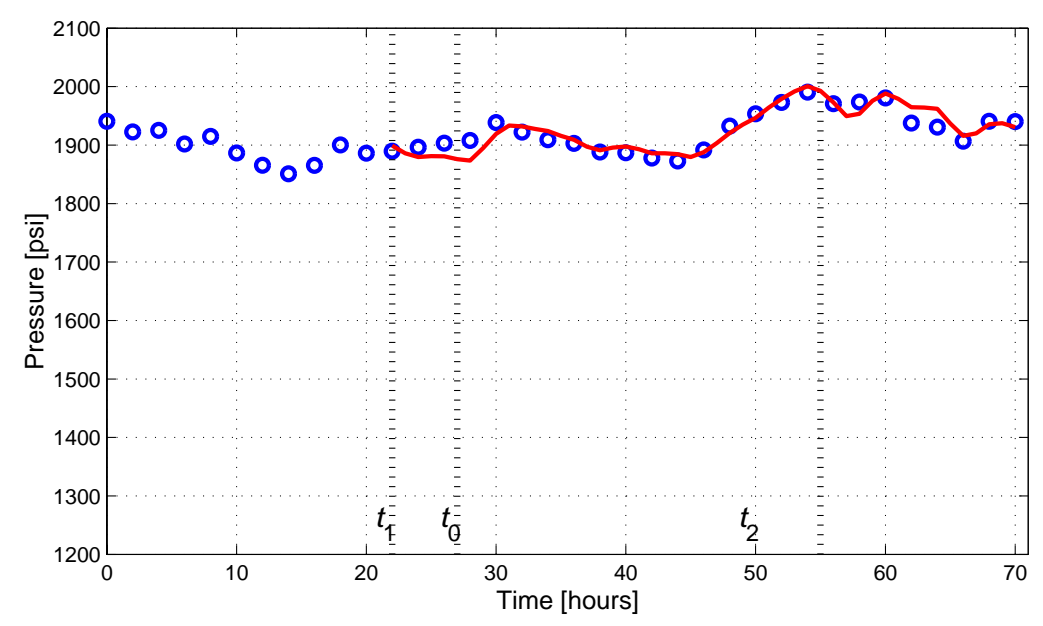

(b)

Figure 5. Well D: The quality of fitting is stable with respect to the selection of the interval and regardless of whether the data are smoothed (b) or not (a). 


\section{Conclusions}

A new well test analysis method accounting for pre-test operations has been applied to analyze regular injection data during normal operations in real field conditions. We used as the main tool the code ODA, which implements the new method developed by Silin and Tsang $(2002,2003)$. Key parameters are the transmissivity and storativity of the formation in the vicinity of the wellbore. As byproducts, the method also produces estimates of the skin factor and the effective pre-test pumping rate parameter. The latter can be used for additional verification of the quality of analysis.

Results from data analysis confirm the possibility of estimating the formation hydraulic properties and monitoring their changes over time, using regular operations data instead of or in conjunction with conventional well tests. The ODA method is based on analysis of large data intervals, and the flexibility in the selection of such intervals makes possible detection of variations of formation properties caused by changing the regime of operations. The recovered transmissivity factor is stable with respect to the selection of the data interval, so that a value of reasonable confidence can be obtained. The effective pre-test pumping rate is close to the actual flow rate prior to the test interval, which provides additional confirmation of the results.

To summarize, the applicability of this new method for estimating formation hydraulic properties based on regular operations data has been confirmed. The code ODA makes such analysis simple and inexpensive. Implementation of this method in the field can lead to automation of the process of formation properties monitoring without interrupting regular operations.

\section{Acknowledgments}

This research has been supported by the U.S. Environmental Protection Agency (EPA), Office of Ground Water and Drinking Water, Underground Injection Control Program, under an Interagency Agreement with the US Department of Energy under Contract No. DE-AC03-76SF00098. The authors are thankful to BP Chemicals of Lima, Ohio, for providing the field data.

\section{References}

Earlougher, R.C., 1977. Advances in Well Test Analysis. Monograph Series, 5. Society of Petroleum Engineers, New York.

Matthews, C.S., and Russell, D.G., 1967. Pressure Buildup and Flow Tests in Wells. Monograph Series. Society of Petroleum Engineers, New York.

Silin, D.B. and Tsang, C.-F., 2002. Estimation of Formation Hydraulic Properties Accounting for Pre-Test Injection or Production Operations. Journal of Hydrology, 265(1): 1-14.

Silin, D.B. and Tsang, C.-F., 2003. A Well-Test Analysis Method Accounting for PreTest Operations. SPE Journal (March): 22-31.

Theis, C.V., 1935. The Relationship between the Lowering of the Piezometric Surface and the Rate and Duration of Discharge of a Well Using Ground-Water Storage. Transactions AGU, 2: 519-524. 